\title{
The Role of Aspergillus parasiticus NRRL:3386 Strain on Petroleum Biodegradation and Biosorption Processes
}

\author{
Sezen Bilen Ozyurek ${ }^{\mathbb{D}}$, Nermin Hande Avcioglu ${ }^{1}$ (D) \\ 'Hacettepe University, Faculty of Science, Department of Biology, Ankara, Turkey
}

ORCID IDs of the authors: S.B.O. 0000-0002-5056-7051; N.H.A. 0000-0003-2243-5817

Please cite this article as: Bilen Ozyurek S, Avcioglu NH. The Role of Aspergillus parasiticus NRRL:3386 Strain on Petroleum Biodegradation and Biosorption Processes. Eur J Biol 2020; 79(2): 144-150. DOI: 10.26650/EurJBiol.2020.0099

\begin{abstract}
Objective: Fungi play an important role in the removal of hazardous organic compounds from the environment with their extracellular multiple enzyme systems. In the bioremediation processes, fungi act as a bioreactor by breaking down or are biosorbent by accumulating organic pollutants.

Materials and Methods: The aim of this study was to investigate and to compare the biodegradation and biosorption capacities of different amounts of live and dead biomasses and different concentrations of culture supernatants of Aspergillus parasiticus NRRL:3386 with gravimetric, gas chromatography-mass spectrometry (GC/MS) and scanning electron microscope (SEM) analyses.

Results: This study indicated that $1 \mathrm{~g}$ of live biomass degraded $80 \%$ of petroleum within 4-days of incubation. The cellfree culture supernatant was not as effective as the live biomass in petroleum degradation. The petroleum biosorption was achieved at over $50 \%$ by $1 \mathrm{~g}$ and $2.5 \mathrm{~g}$; over $70 \%$ by $5 \mathrm{~g}$ and $7.5 \mathrm{~g}$, and over $80 \%$ by $10 \mathrm{~g}$ of dead biomasses. The petroleum removal efficiencies of $2 \mathrm{~g}$ of live and $10 \mathrm{~g}$ of dead biomasses were over $80 \%$. GC/MS analysis demonstrated that $C_{10}-C_{18}$ $n$-alkanes (except $C_{11}$ and $C_{13}$ ) and $C_{11}, C_{13}, C_{19}-C_{26} n$-alkanes were degraded $47-77 \%$ and over $80 \%$, respectively. The moststriking result was that $C_{27}-C_{33} n$-alkanes were efficiently degraded over $90 \%$ in a short incubation period. SEM analysis showed that gaps between fungal hyphae were clear and bright before biosorption of petroleum, whereas gaps between fungal hyphae were closed after biosorption of petroleum.
\end{abstract}

Conclusion: The results clearly pointed out that $A$. parasiticus will make a significant contribution to advanced mycoremediation studies.

Keywords: Aspergillus parasiticus NRRL:3386, petroleum, biosorption, biodegradation, Gas Chromatography-Mass Spectrometry, Scanning Electron Microscope

\section{INTRODUCTION}

Petroleum is a non-renewable resource that provides most of the world's energy (1). In addition to being a significant energy source in daily life, petroleum hydrocarbons are an important source of raw materials for industrial chemicals (2). As petroleum is a complex hydrocarbon mixture of saturated hydrocarbons, aromatic hydrocarbons and polar organic compounds, it damages the lungs, kidneys, liver, intestines and other internal organs of living organisms and also causes environmental pollution. Environmental pollution which is caused by petroleum and petroleum derivatives is one of the most important problems of developing countries (3). Refining, storing and transporting high amounts of petroleum hydrocarbons to fulfill the increase in energy demand, has led to oil spills in large scale areas (4). Remediation of oil spills by chemical and physical remediation methods provide an improvement of $40-50 \%$. However, these methods are quite complex, expensive and time consuming and untreated biodegradable particles are still left in the environment $(1,5)$. In this regard, the most effective approach to the remediation of petroleum contaminated areas 
is the use of biological methods (5). Microbial enhanced oil recovery (MEOR) is a cost-effective and environmentally friendly technique. The primary mechanism in MEOR aims to increase the fluidity and decrease the viscosity of petroleum as a result of biodegradation of long chain saturated hydrocarbons by microbial activity. The biodegradation of petroleum hydrocarbons is carried out by bacteria, fungi and algae with their microbial enzymes. Bacteria have oxygenase and dehydrogenase, while fungi have dehydrogenase and membrane-bound cytochrome P450 as common enzymes. Most microorganisms biodegrade petroleum hydrocarbons via aerobic pathways; however the anaerobic degradation of long chain $n$-alkanes is important for MEOR due to a lack of oxygen in reservoir systems. Additionally, fungal enzymes can degrade $n$-alkanes of petroleum to lower fractions in oxygen-deprived conditions and can be used as an alternative to oxygen-depleting microorganisms with low growth in reservoirs $(1,3)$.

Many microorganisms can use petroleum hydrocarbons as carbon and energy sources and convert them into $\mathrm{CO}_{2}, \mathrm{H}_{2} \mathrm{O}$ and nontoxic products (4). While the research in literature is limited to bacterial remediation, the usage of potential fungal strains in remediation processes, is very important in the development of new mycoremediation strategies (5). Fungi are highly capable of degrading complex structures and long chain hydrocarbons and are more resistant to the toxic effects of petroleum hydrocarbons than bacteria (4). In addition to the biodegradation of toxic petroleum hydrocarbons, the surface adsorption and cell absorption of different petroleum hydrocarbons by fungi are noteworthy. It was clearly shown in the literature that the most effective fungi in the bioremediation of petroleum are Aspergillus sp., Penicillium sp., Cephalasporium sp., Rhizophus sp., Fusarium sp., Rhodotorula sp., Paecilomyces sp., Torulopsis sp., Pleutrotus sp., Alternaria sp., Mucor sp., Talaromyces sp., Cladosporium sp., and Geotrichum sp., (6-10). In the bioremediation process, fungi are advantageous compared to bacteria due to potential hydrolytic enzymes and fungal hyphae facilitating penetration. Filamentous fungi can use various substrates with their extracellular hydrolytic enzymes. Thus, they have hydrocarbon biodegradation capabilities as their biodegrading enzyme systems are extracellular and nonspecific. In addition, fungal enzymes can be obtained by high efficiency and low-cost methods. Having a short enzymolysis time with the unique biodegradation capabilities of fungi, this process does not require the use of living microorganisms. All these features of fungi make them unique for industrial usage derivatives $(1,3)$. Although the biodegradation of petroleum hydrocarbons with different bacterial strains, bacterial consortia and fungal strains have been investigated in various studies in Turkey, no similar study has been found on biodegradation and biosorption of petroleum by Aspergillus parasiticus NRRL:3386 (11-13). In this context, the study aimed to determine and to compare biodegradation and biosorption capacities of petroleum by different amounts and concentrations of live/dead biomasses and culture supernatants of $A$. parasiticus NRRL:3386 with gravimetric, Gas Chromatography/Mass Spectrometry (GC/ MS) and Scanning Electron Microscopy analyses (SEM).

\section{MATERIALS AND METHODS}

\section{Sampling}

$1 \mathrm{~L}$ of petroleum sample was collected from an oil field (Diyarbakir, Turkey) and transported to the Environmental Biotechnology Laboratory in Hacettepe University, Beytepe, Ankara, Turkey.

\section{Inoculum Preparation and Storage}

The pure culture of $A$. parasiticus NRRL:3386 strain was inoculated onto potato dextrose agar and incubated at $30^{\circ} \mathrm{C}$ for a week. The fungal cultures were stored at $+4^{\circ} \mathrm{C}$ in Hacettepe University Culture Collection Laboratory, Beytepe, Ankara, Turkey.

\section{Preparation of Fungal Biomass}

The pure culture of fungal strain was inoculated in potato dextrose broth (PDB) and the incubation process was carried out at $30^{\circ} \mathrm{C}$ and 150 rpm for 7 days (IKA ${ }^{\oplus} \mathrm{KS} 4000 \mathrm{i}$, Germany) (14). Following the incubation period, the fungal cultures were filtered using Whatman No: 1 filter paper under sterile conditions. Fungal pellets drying in sterile petri dishes at $30^{\circ} \mathrm{C}$ in a static incubator (Mipro $\mathrm{MCl}$, Turkey), were used as live biomass. Filter-dried fungal pellets were autoclaved at $121^{\circ} \mathrm{C}$ for 15 minutes and the pellets were used as dead biomass.

\section{Preparation of Cell-Free Culture Supernatant}

The pure culture of fungi was inoculated into Bushnell Haas $(\mathrm{BH})$ (g/L: $0.2 \mathrm{MgSO}_{4^{\prime}} 0.02 \mathrm{CaCl}_{2^{\prime}} 1 \mathrm{KH}_{2} \mathrm{PO}_{4^{\prime}} 1 \mathrm{~K}_{2} \mathrm{HPO}_{4^{\prime}} 1 \mathrm{NH}_{4} \mathrm{NO}_{3^{\prime}} 0.05$ $\mathrm{FeCl}_{3}$ ) (Sigma-Aldrich) medium with $1 \%$ sterile petroleum and the incubation process was carried out at $30^{\circ} \mathrm{C}$ and $150 \mathrm{rpm}$ for 7 days (IKA ${ }^{\oplus}$ KS 4000i, Germany). Following the incubation period, the fungal cultures were filtered using Whatman No: 1 filter paper under sterile conditions. The filtrate was used as the cellfree culture supernatant for petroleum biodegradation assays.

\section{Petroleum Biodegradation and Biosorption}

$\mathrm{BH}$ medium was used for biodegradation and biosorption of petroleum by $A$. parasiticus NRRL:3386. $0.1 \%$ glucose, $0.1 \%$ yeast extract and 1\% Triton X:100 were added in $\mathrm{BH}$ medium as an additional carbon, nitrogen and surfactant sources, respectively. Following the sterilization process and cooling to $45^{\circ} \mathrm{C}$ of $\mathrm{BH}$ medium $\left(121^{\circ} \mathrm{C}\right.$ for $\left.15 \mathrm{~min}\right), 1 \%$ of sterilized petroleum $(0.22 \mu \mathrm{m}$ cellulose acetate syringe filter) (Millipore, Sartorius) was also added. The different amounts of live/dead biomasses and concentrations of culture supernatants were inoculated into the medium and the incubation process was carried out at $30^{\circ} \mathrm{C}$ and $150 \mathrm{rpm}$ for the appropriate period in dark conditions (IKA ${ }^{\oplus}$ KS 4000i, Germany). The experiments were performed in triplicate (15).

\section{Gravimetric Analysis}

The biodegradation and biosorption of petroleum were determined by modifying the method recommended by Al-Hawash et al. (4). Following the incubation period, petroleum biodegradation and biosorption were evaluated with gravimetric analysis. The residual petroleum was extracted with dichloromethane $\left(\mathrm{CH}_{2} \mathrm{Cl}_{2}\right)$ (1:2) (Sigma-Aldrich) and then the upper phase was also removed. To evaporate the dichloromethane, the flasks were left at $90{ }^{\circ} \mathrm{C}$ for half an hour (Memmert, Schwabach, Germany). The degradation of petroleum was calculated as: 
$D(\%)=\left(p_{0}-p_{1}-p_{2}\right) / p_{0} \times 100$

where $p_{0}$ and $p_{1}$ indicate the initial and remaining concentrations of petroleum at different incubation periods, $p_{2}$ denotes the concentration of abiotic loss.

The specific degradation rate was also calculated as follows:

$d_{\mathrm{x}} / x_{0} \cdot d_{\mathrm{t}}$

where $d_{x}$ is the change in concentration of the petroleum, $x_{0}$ shows the petroleum concentration and $d_{t}$ indicates a time interval $(10,16)$.

\section{Degradation Kinetics}

The degradation of petroleum follows the first-order reaction kinetics; it can be calculated as:

$\ln n_{\mathrm{ct}}=\ln _{\mathrm{co}}-K_{\mathrm{t}}$

where $c_{\mathrm{t}}$ and $c_{\mathrm{o}}$ show the residual and initial petroleum concentrations; $K$ indicates first-order reaction speed constant for petroleum biodegradation $\left(\right.$ day $\left.^{-1}\right)$, and $t$ is time (day). The half-life period of petroleum can be calculated as follows:

$t_{1 / 2}=\ln 2 / k$

where $\mathrm{k}$ is the biodegradation rate constant $\left(\right.$ day $\left.^{-1}\right)(10,16)$.

\section{Effect of the Incubation Period on Biodegradation of Petro-} leum

$1 \mathrm{~g}$ of live biomass was inoculated into $\mathrm{BH}$ medium and incubation process was carried out at $30^{\circ} \mathrm{C}$ and $150 \mathrm{rpm}$ for 7 days (IKA ${ }^{\circledR}$ KS 4000i, Germany). The degradation of petroleum was obtained by gravimetric analysis.

\section{Effect of Different Amounts of Live Biomasses on Biodegra- dation of Petroleum}

$0.25,0.5,1,1.5$ and $2 \mathrm{~g}$ of live biomasses were inoculated into $\mathrm{BH}$ medium and the incubation process was carried out at $30^{\circ} \mathrm{C}$ and $150 \mathrm{rpm}$ for an appropriate period (IKA ${ }^{\oplus} \mathrm{KS} 4000 \mathrm{i}$, Germany). The degradation of petroleum was obtained by gravimetric analysis.

\section{Effect of Different Concentrations of Culture Supernatant on Biodegradation of Petroleum}

$2.5 \%, 5 \%, 7.5 \%$ and $10 \%$ concentrations of culture supernatants were inoculated into $\mathrm{BH}$ medium and the incubation process was carried out at $30^{\circ} \mathrm{C}$ and $150 \mathrm{rpm}$ for an appropriate period (IKA ${ }^{\oplus}$ KS 4000i, Germany). The degradation of petroleum was obtained by gravimetric analysis.

\section{Effect of Different Amounts of Dead Biomasses on Biosorp- tion of Petroleum}

$1,2.5,5,7.5$ and $10 \mathrm{~g}$ of dead biomasses were inoculated into $\mathrm{BH}$ medium and the incubation process was carried out at 30 ${ }^{\circ} \mathrm{C}$ and $150 \mathrm{rpm}$ for an appropriate period. The degradation of petroleum was obtained by gravimetric analysis.

\section{SEM Analysis}

SEM analysis was carried out by Hacettepe University Advanced Technologies Application and Research Center using with Zeiss
EVO 50 SEM (Germany). The samples were coated with carbon. The biosorption of petroleum by dead biomass of $A$. parasiticus was determined by SEM micrograph.

\section{GC/MS Analysis}

GC-MS analysis was performed to determine the removal of $n$-alkane fractions in petroleum with A. parasiticus NRRL:3386 strain. GC/MS analysis was carried out by the Petroleum Research Center at Middle East Technical University using TRB-1 GCMS-QP-2020 (Shimadzu, Tokyo, Japan). The procedure was performed according to Ozyurek and Bilkay (16).

\section{RESULTS}

The Petroleum Degradation by Different Incubation Periods and Different Amounts of Live Biomasses

In the first step of this study, the incubation periods (1-7 days) and the amounts of live biomasses $(0.25,0.5,1,1.5$ and $2 \mathrm{~g}$ ) were investigated to determine the most effective petroleum degradation by live biomass of $A$. parasiticus. As shown in Figure 1 , the degradation of petroleum by $1 \mathrm{~g}$ of live biomass reached

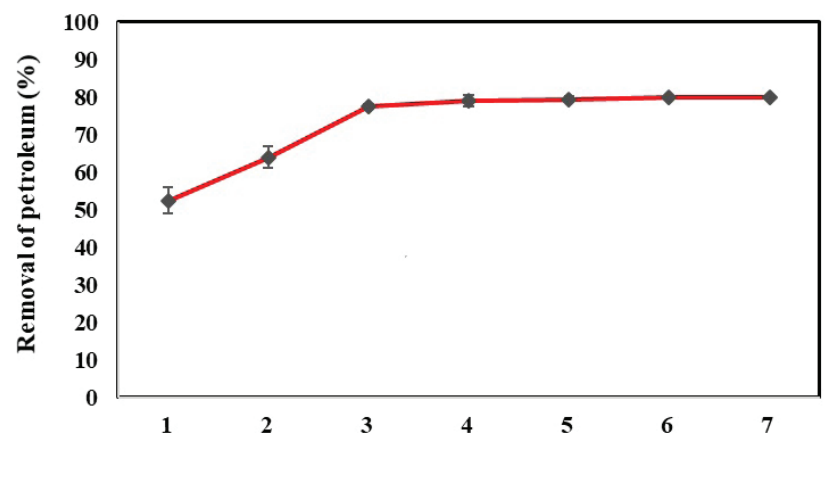

Incubation period (days)

Figure 1. The effect of different incubation periods on biodegradation of petroleum by live biomass of $A$. parasiticus Growth of A. parasiticus strain was carried out at $30{ }^{\circ} \mathrm{C}$ and 150 rpm for 7 days. Results are average of three measurements. Standard deviations are shown on graph.

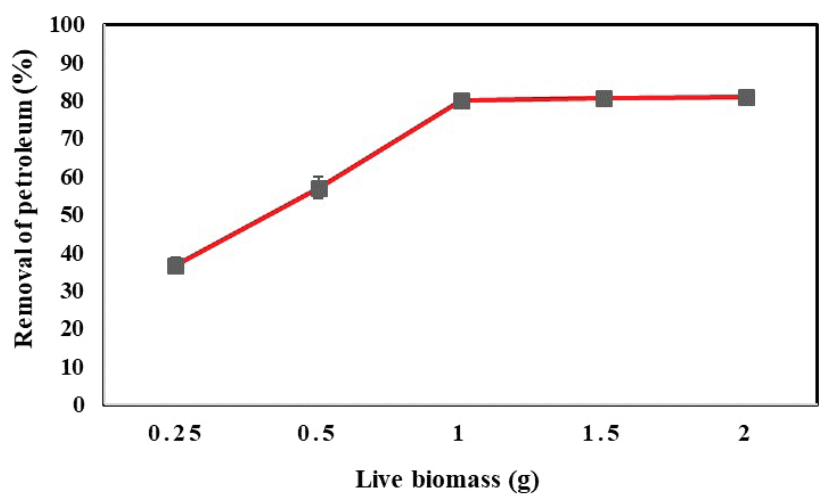

Figure 2. The effect of different amounts of live biomasses on biodegradation of petroleum. Growth of $A$. parasiticus strain was carried out at $30^{\circ} \mathrm{C}$ and $150 \mathrm{rpm}$ for 4 days. Results are average of three measurements. Standard deviations are shown on graph. 
$80 \%$ at the $4^{\text {th }}$ day of the incubation period. There was no significant increase in the removal of petroleum after the $4^{\text {th }}$ day. Additionally, Figure 2 also demonstrates that above $1 \mathrm{~g}$ of live biomass, there was no dramatic effect on removal of petroleum. According to these results, the specific degradation rate was calculated as 0.200 . In the control sample, the specific degradation rate was also calculated as 0.002 day $^{-1}$ for petroleum. The degradation rate constant and half-life period of live biomass of A. parasiticus NRRL:3386 were calculated as 1.609 day $^{-1}$ and $t_{1 / 2}=$ 0.431 . So, it is clearly demonstrated that half-life period was low with high degradation rate constant.

\section{The Petroleum Degradation by Different Concentrations of Cell-Free Culture Supernatants}

The effect of different concentrations (2.5\%, 5\%, 7.5\% and 10\%) of cell-free culture supernatants on petroleum biodegradation were evaluated. As shown in Figure 3, the culture supernatant containing extracellular enzymes had no significant effect on petroleum biodegradation. Thus, increasing the concentration

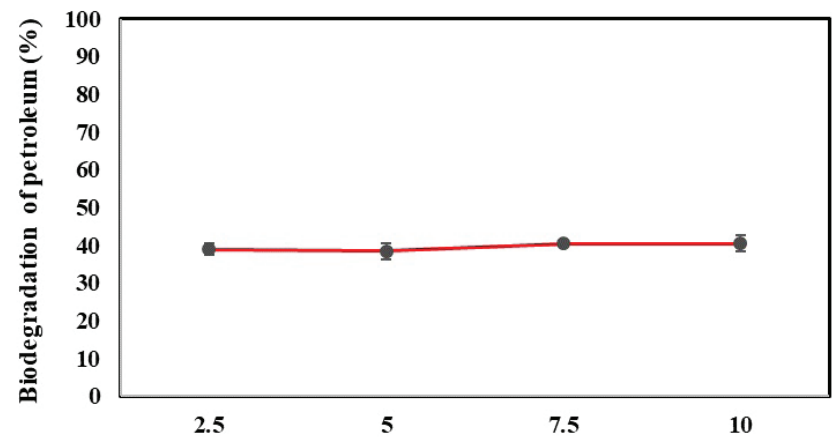

Cell-free culture supernatant (\%)

Figure 3. The effect of different concentrations of cell-free culture supernatants on biodegradation of petroleum. Growth of $A$. parasiticus strain was carried out at $30^{\circ} \mathrm{C}$ and $150 \mathrm{rpm}$ for 4 days. Results are average of three measurements. Standard deviations are shown on graph.

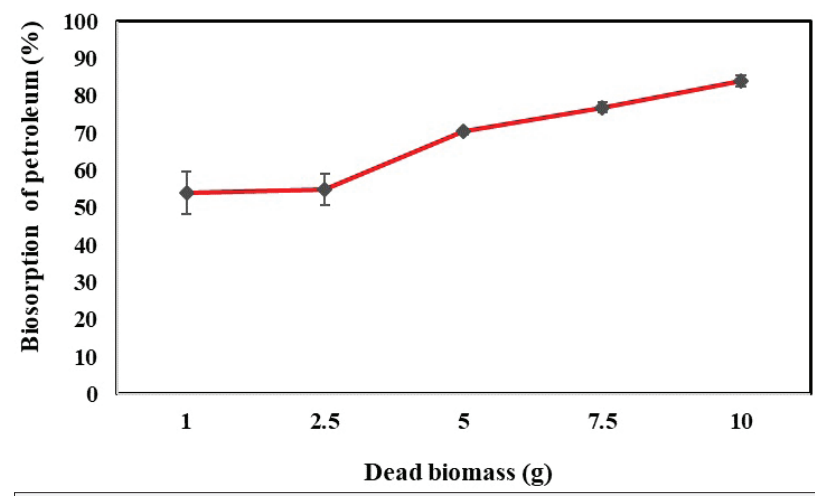

Figure 4. The effect of different amounts of dead biomasses on biosorption of petroleum. Growth of A. parasiticus strain was carried out at $30^{\circ} \mathrm{C}$ and $150 \mathrm{rpm}$ for 4 days. Results are average of three measurements. Standard deviations are shown on graph. of culture supernatants did not lead to the expected effect on biodegradation of petroleum.

\section{The Petroleum Biosorption by Different Amounts of Dead Biomasses}

The effect of different amounts (1, 2.5, 5, 7.5 and $10 \mathrm{~g})$ of dead biomasses were evaluated for petroleum biosorption. Figure 4 shows that over $50 \%$ of petroleum biosorption was observed
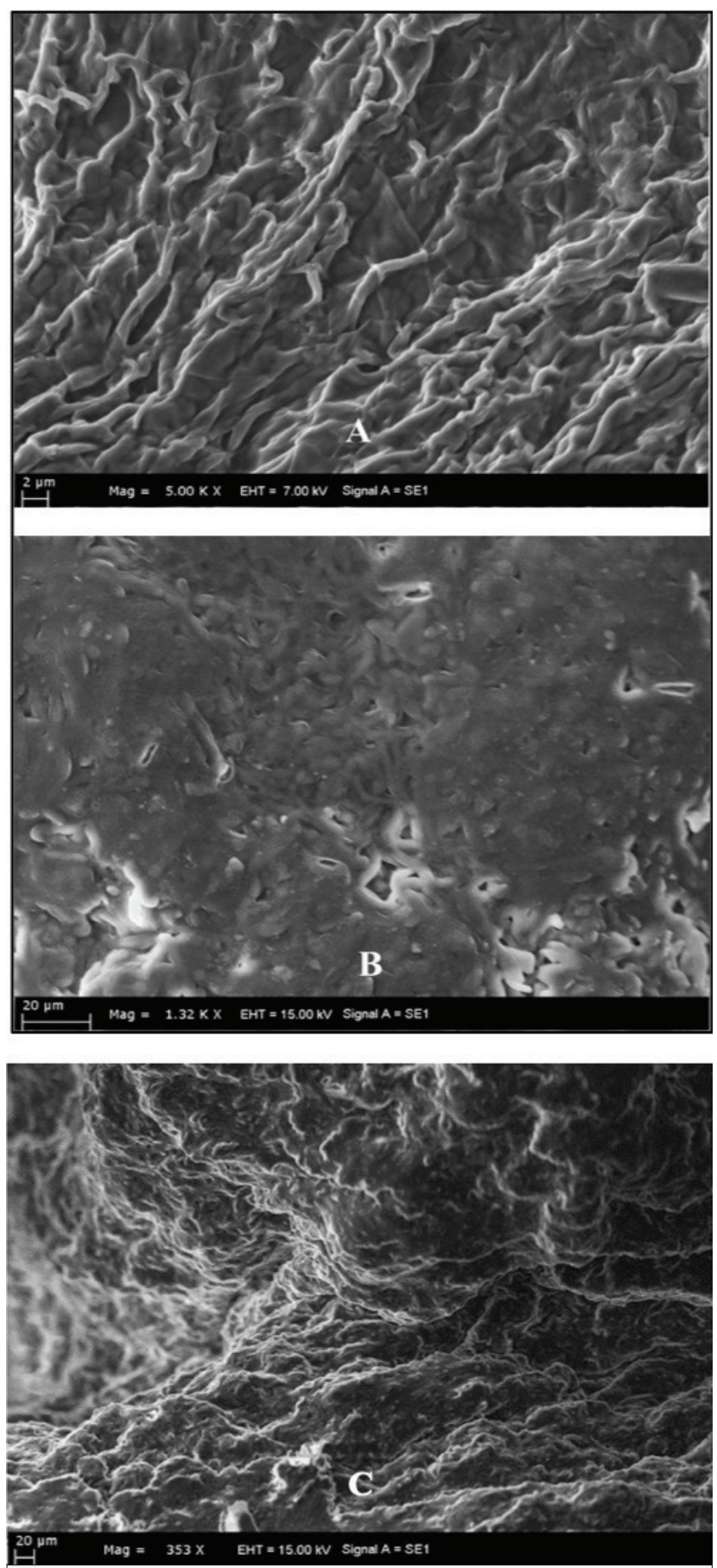

Figure 5. SEM micrograph of dead biomass of $A$. parasiticus: (A) before and $(B, C)$ after biosorption of petroleum. 


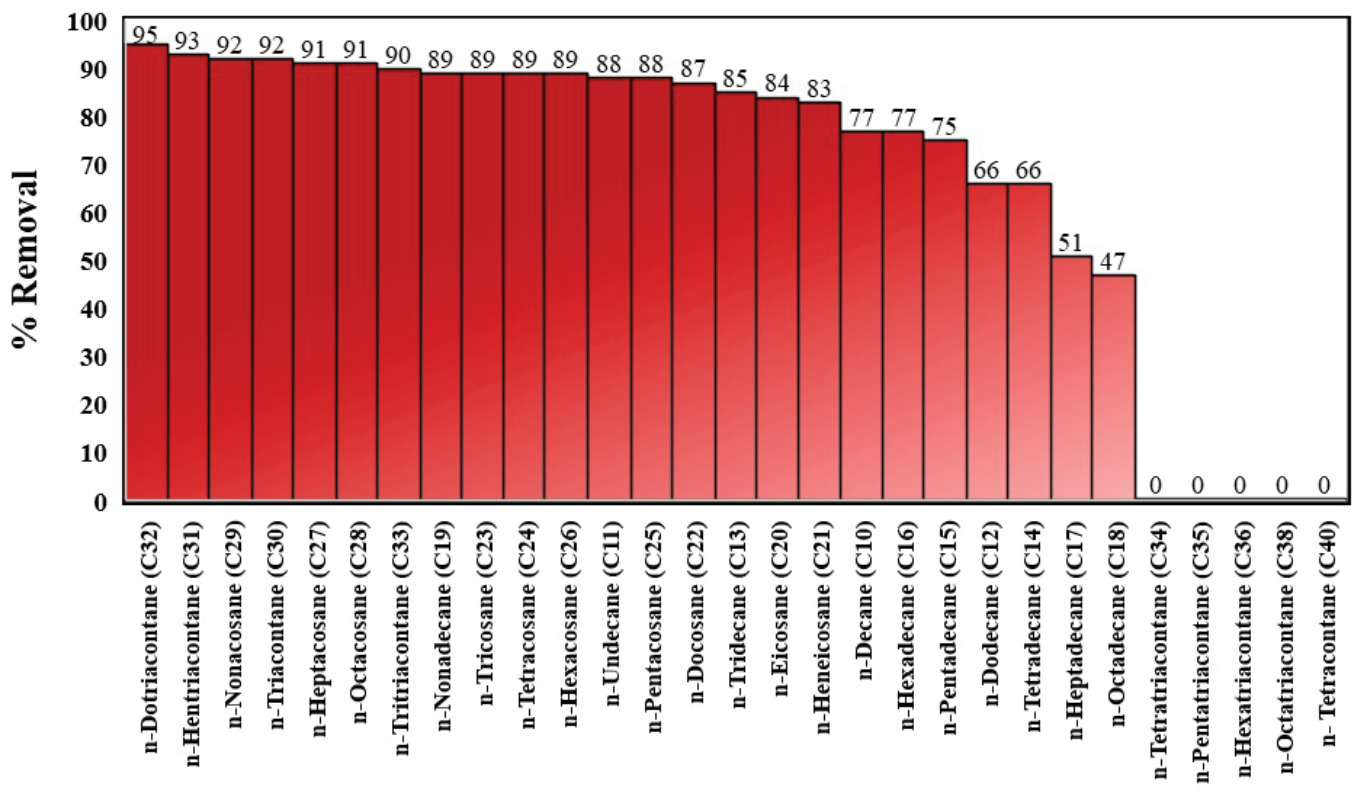

n-alkane hydrocarbons

Figure 6. The degradation of $\mathrm{n}$-alkane hydrocarbons by A. parasiticus. Growth of $A$. parasiticus strain was carried out at $30{ }^{\circ} \mathrm{C}$ and 150 rpm for 4 days.

with 1 and $2.5 \mathrm{~g}$ of dead biomasses. Furthermore, over 70\%, $70 \%$, and $80 \%$ of petroleum biosorption was detected with $5 \mathrm{~g}$, $7.5 \mathrm{~g}$ and $10 \mathrm{~g}$ of dead biomasses, respectively.

\section{SEM Results}

SEM is used to verify the morphological differences between the dead biomass of $A$. parasiticus NRRL:3386 before and after biosorption of petroleum. While the gaps between hyphae of fungi are clear and bright before petroleum biosorption, it has been shown that the gaps between hyphae of fungi are closed due to the accumulation of petroleum. SEM micrographs of dead biomasses of fungi are shown in Figures $5 \mathrm{~A}-\mathrm{C}$.

\section{GC/MS Results}

As shown in Figure $6, C_{10}-C_{18}$ short chain $n$-alkanes (except $C_{11}$ and $C_{13}$ ) were biodegraded in the range of $47-77 \%$ and $C_{11^{\prime}} C_{13^{\prime}}$ and $C_{19}-C_{26} n$-alkanes were degraded over $80 \%$. Moreover, long chain $n$-alkanes in the $C_{27}-C_{33}$ range were efficiently degraded over $90 \%$ by $1 \mathrm{~g}$ of live biomass of $A$. parasiticus NRRL:3386.

\section{DISCUSSION}

Petroleum hydrocarbons are used as carbon and energy sources by fungal strains $(10,17)$. Aspergillus sp. plays an important role in the biodegradation of a wide range of petroleum hydrocarbons. Accordingly, live biomass of fungi is both degrading and accumulating organic pollutants during the bioremediation process. In this manner, this study focused on the biodegradation and biosorption of petroleum by live/dead biomasses and culture supernatant of $A$. parasiticus NRRL:3386 strain. Because filamentous fungi ( $A$. parasiticus) is an important potential agent on removal of petroleum by its ability to rapidly bind to substrates and being able to grow under environmental conditions, $80 \%$ of petroleum degradation was observed by 1 $\mathrm{g}$ of live biomass of $A$. parasiticus NRRL:3386 within only 4-days of the incubation period. The degradation rate constant and half-life period of live biomass of $A$. parasiticus NRRL:3386 were 1.609 day $^{-1}$ and $t_{1 / 2}=0.431$. Similar studies clearly showed that the half-life period was low with a high degradation rate constant $(18,19)$. In the literature, Aspergillus sp. and Rhizopus sp. were found to be effective in the biodegradation of petroleum and lubricating oil $(4,6,20)$. Al-Hawash et al. demonstrated that Penicillium sp. RMA1 degraded petroleum at $57 \%$ in 14 days (10). Maddela et al. reported that two fungal isolates degraded $79.9 \%$ of petroleum in 30 days (17). About $60 \%$ of biodegradation of petroleum was performed by different Aspergillus strains (A. flavus, A. fumigatus, A. versicolor, A. terreus) after 7 days of the incubation period and the biodegradation of petroleum was over $80 \%$ after 28 days (5). Although an increase in the incubation period usually led to an increase of petroleum biodegradation in different studies, the increase in incubation period did not lead to a significant increase in the removal of petroleum in this study (Figure 1). With the increase in incubation period, toxic compounds increase with the decrease of nutrients in the culture. So, it is thought that the fungi reached high petroleum biodegradation in a short incubation period.

Fungi with a large enzymatic activity are highly effective in the biodegradation of petroleum hydrocarbons. It is known that fungal enzymes such as hydrocarbon oxidoreductase, laccase and peroxidase play an important role in the bioremediation of sea water, fresh waters and soil (3). The extracellular enzymes produced by Aspergillus sp. have a significant effect on the 
biodegradation of petroleum (4). However, it was found in this study that the culture supernatant of fungi was not effective in biodegradation of petroleum (Figure 3). Because the live biomass of fungi acts both as a bioreactor by breaking down organic pollutants by their intracellular and extracellular enzymes and biosorbent by accumulating organic pollutants during the bioremediation process, the culture supernatant was not as effective as live biomass on the removal of petroleum (21).

Fungi play an important role in biosorption of petroleum as well as biodegradation (4). Biosorption is a physicochemical process in which chemicals are entrapped in or on the surfaces of biological matrices (21). This passive bioaccumulation process (biosorption) is highly selective and efficient so it can be used in large scale improvements. In addition, no hazardous products are produced in this process (22). Biosorption of hydrocarbons can occur with three basic mechanisms. In the first mechanism, the hydrocarbons dissolved in the aqueous phase are directly absorbed by microbial cells, this mechanism is more suitable for cell uptake of short-chain hydrocarbons. In the second mechanism, small hydrocarbon droplets that are melted or close to melting are absorbed by microbial cells. In the third mechanism, hydrocarbons are transported by active transport or diffusion into the microbial cell by establishing a direct contact. It is known that petroleum hydrocarbons are absorbed by microbial cells by the second and third mechanism (4). In this context, 5, 7.5 and $10 \mathrm{~g}$ of dead biomasses achieved over $70 \%, 70 \%$ and $80 \%$ of petroleum biosorption, respectively. Because the surface area of the adsorbent plays an important role in the adsorption of petroleum hydrocarbons in aqueous media, the highest biosorption of petroleum was performed by $10 \mathrm{~g}$ of dead biomass (Figure 4) (4). SEM analysis emphasized the difference of surface morphology in dead biomass after biosorption of petroleum. Dead biomass of $A$. parasiticus exhibited a uniform interconnected structure with a continuous surface and the gaps between the hyphae of fungi are very clear and bright in Figure 5a. Due to accumulation of petroleum, the gaps between the hyphae of fungi are closed in Figures $5 b$ and $5 c$.

When the removal efficiencies of live and dead biomasses were compared, over $80 \%$ of petroleum removal were achieved using $2 \mathrm{~g}$ of live biomass and $10 \mathrm{~g}$ of dead biomass of fungi (Figures 2 and 4). So, it can be expressed that the removal of petroleum can be achieved not only by live biomass which is active due to its enzymes but also by dead biomass which acts as a biological material. Because living microorganisms are affected by nutrients, $\mathrm{pH}$ and other environmental conditions, the usage of inactivated biological materials is very advantageous in the removal of toxic organic compounds such as petroleum. In a similar study, the biodegradation and biosorption activities of live and dead mycelial pellets of Penicillium chrysogenum on different PAHs were investigated. It was determined that the removal of phenanthrene by live and dead mycelial pellets of $P$. chrysogenum were similar. However, the removal of pyrene by dead mycelial pellets was higher than that re- moved by live mycelial pellets of $P$. chrysogenum. Although the removal of pyrene by the live mycelial pellets was higher than phenanthrene, the removal capacities of live mycelial pellets were also low compared to dead mycelial pellets. Due to the change in permeability of $P$. chrysogenum cells in high-pressure inactivation process, dead mycelial pellets showed high biosorption efficiencies (21).

The GC/MS analysis of $A$. parasiticus also shows that short- and medium-chain $n$-alkanes were degraded in the range of 47 - 89\% (Figure 6). Many bioremediation studies have demonstrated that fungi are generally effective on short- and medium-chain $n$-alkanes in the removal process of petroleum. RMA1 and RMA2 fungal strains degraded $n$-alkanes in the range of $C_{11}-C_{20}$ and $C_{21}-C_{25}$. Aliphatic hydrocarbons such as $n$-undecane, $n$-dodecane, $n$-tridecane, $n$-tetradecane, $n$-pentadecane and $n$-hexane were used by fungal strains (10). Zhang et al. reported that Geobacillus sp. degraded only $n$-alkane fractions in the range of $\mathrm{C}_{12}-\mathrm{C}_{21}$ in crude oil (23). Hadibarata and Tachibana reported that the Trichoderma S019 strain was effective on $n$-eicosane $\left(C_{20}\right)$ in the presence of glucose as an additional carbon source (24). Folsomia candida, isolated from the petroleum contaminated area, degraded $79 \%$ of mediumand long-chain aliphatic hydrocarbons (25). The recent studies have clearly indicated that the increase in the density of petroleum hydrocarbons and number of rings in polycyclic aromatic hydrocarbons cause a decrease in the biodegradation process (4). In contrast to the studies in literature, it was quite striking that over $90 \%$ of long chain $n$-alkanes were degraded effectively by $A$. parasiticus. The fungi showed a significant effect in the biodegradation of long chain $n$-alkanes, which are more resistant to biodegradation. So, it should be emphasized that A. parasiticus, which has a complex enzyme system, is capable of greatly degrading complex structure of long chain hydrocarbons (2).

\section{CONCLUSION}

Aspergillus parasiticus NRRL:3386 had a significant effect on biodegradation and biosorption processes of petroleum in a short incubation period. The biodegradation and biosorption capacities of $2 \mathrm{~g}$ of live biomass and $10 \mathrm{~g}$ of dead biomass were over $80 \%$ within 4-days. Furthermore, $1 \mathrm{~g}$ of live biomass degraded $80 \%$ of petroleum in a short incubation period. While short and medium chain $n$-alkanes were degraded in the range of $47-$ $89 \%$, it was quite striking that long chain $n$-alkanes were broken down more than $90 \%$ within 4 days. Many bioremediation studies in the literature have shown that fungal strains are generally effective on short- and medium-chain $n$-alkanes in the removal process of petroleum. However, the A. parasiticus strain showed a considerable effect on removal of long chain $n$-alkanes compared to short- and medium-chains. The results of this study clearly indicated that biodegradation and the biosorption capacities of $A$. parasiticus were considerably high. It is believed that this study will provide an important contribution to further mycoremediation studies in the literature. 
Peer-review: Externally peer-reviewed.

Author Contributions: Conception/Design of study: S.B.O., N.H.A.; Data Acquisition: S.B.O., N.H.A.; Data Analysis/Interpretation: S.B.O., N.H.A.; Drafting Manuscript: S.B.O., N.H.A.; Critical Revision of Manuscript: S.B.O., N.H.A.; Final Approval and Accountability: S.B.O., N.H.A.; Supervision: S.B.O., N.H.A.

Conflict of Interest: The authors declare that they have no conflicts of interest to disclose.

Financial Disclosure: There are no funders to report for this submission.

Acknowledgements: The authors would like to thank all staff in the Hacettepe University Biotechnology Laboratory for supporting and contributing to this work.

\section{REFERENCES}

1. Zhang JH, Xue QH, Gao H, Ma X, Wang P. Degradation of crude oil by fungal enzyme preparation from Aspergillus spp. For potential use in enhanced oil recovery. J Chem Technol Biotechnol 2016, 91: 865-75.

2. Fan CY, Krishnamurth S. Enzymes for enhancing bioremediation of petroleum-contaminated soils: A brief review. J Air Waste Manag Assoc 1995, 45: 453-9.

3. Balaji V, Aruzlazhagan P, Ebenezer P. Enzymatic bioremediation of polyaromatic hydrocarbons by fungal consortia enriched from petroleum contaminated soil and seeds. J Environ Biol 2014, 35: 1-9.

4. Al-Hawash AB, Zhang X, Ma F. Removal and biodegradation of different petroleum hydrocarbons using filamentous fungus Aspergillus sp. RFC-1. Microbiologyopen 2018; 8(1): 1-14.

5. Islam NF. Bioprospecting fungal diversity from crude oil infiltrate soil of Assam, India's Northeast. Trop Plant Res 2017; 4(2): 319-29.

6. Al-Nasrawi $\mathrm{H}$. Biodegradation of crude oil by fungi isolated from Gulf of Mexico. J Bioremediat Biodegrad 2012; 3(4): 1-6.

7. Al-Jawhari IFH. Ability of some soil fungi in biodegradation of petroleum hydrocarbon. J Appl Environ Microbiol 2014; 2(2): 46-52.

8. Vanishree M, Thatheyu A.J, Ramya D. Biodegradation of petroleum using the fungus Penicillium sp. Forensic Sci Int 2014; 2(1): 26-31.

9. Dawoodi V, Madani M, Tahmourespour A, Golshani Z. The study of heterotrophic and crude oil-utilizing soil fungi in crude oil contaminated regions. J Bioremediat Biodegrad 2015; 6(2): 1-5.

10. Al-Hawash AB, Alkooranee JT, Abbood HA, Zhang J, Sun, J, Zhang $X, M a$ F. Isolation and characterization of two crude oil-degrading fungi strains from Rumaila oil field, Iraq Biotechnol Rep 2018; 17: 104-9.

11. Eraydin Erdogan E, Sahin F, Karaca A. Determination of petroleum-degrading bacteria isolated from crude oil-contaminated soil in Turkey. Afr J Biotechnol 2012; 11(21): 4853-9.
12. Ustun Kurnaz S, Buyukgungor H. Bioremediation of total petroleum hydrocarbons in crude oil contaminated soils obtained from southeast Anatolia. Acta Biol Turc 2016; 29(2): 57-60.

13. Bilen Ozyurek S, Seyis Bilkay I. Determination of petroleum biodegradation by bacteria isolated from drilling fluid, waste mud pit and crude oil. Turk J Biochem 2017; 42: 609-16.

14. Tugrul Yucel, T. Investigation of some parameters affecting methyl orange removal by Fusarium acuminatum, Braz Arch Biol Technol 2018; 61: e18160237.

15. Bilen Ozyurek S, Seyis Bilkay I. Biodegradation of petroleum by Klebsiella pneumoniae isolated from drilling fluid. Int J Environ Sci Technol 2018; 15: 2107-16.

16. Bilen Ozyurek S, Seyis Bilkay I. Comparison of petroleum biodegradation efficiencies of three different bacterial consortia determined in petroleum-contaminated waste mud pit. SN Applied Sciences 2020, 272.

17. Maddela NR, Scalvenzi L, Perez M, Montero C, Gooty JM. Efficiency of indigenous filamentous fungi for biodegradation of petroleum hydrocarbons in medium and soil: Laboratory study from Ecuador. Bull Environ Contam Toxicol 2015; 95: 385-94.

18. Yudano B, Said M, Sabaruddin Napoleon A, Fanani Z. Kinetics approach of biodegradation of petroleum contaminated soil by using indigenous isolated bacteria. J Trop Soils 2011; 16: 33-8.

19. Kachieng'a L, Momba, MNB. Kinetics of petroleum oil biodegradation by consortium of three protozoan isolates (Aspidisca sp., Trachelophyllum sp. and Peranema sp.). Biotechnol Rep 2017; 15: 125-31.

20. Thenmozhi R, Arumugam K, Nagasathya A, Thajuddin N, Paneerselvam A. Studies on mycoremediation of used engine oil contaminated soil samples. Adv Appl Sci Res 2013; 4(2): 110-18.

21. Ding J, Chen BL, Zhu LZ. Biosorption and biodegradation of polycyclic aromatic hydrocarbons by Phanerochaete chrysosporium in aqueous solution. Chin Sci Bull 2013; 58: 613-21.

22. Chergui A, Kerbachi R, Junter G-A. Biosorption of hexacyanoferrate (III) complex anion to dead biomass of the basidiomycete Pleurotus mutilus: Biosorbent characterization and batch. Chem Eng J 2009; 147: 150-60.

23. Zhang J, Zhang X, Liu J, Li R, Shen B. Isolation of a thermophilic bacterium Geobacillus sp. SH-1, capable of degrading aliphatic hydrocarbons and naphthalene simultaneously, and identification of its naphthalene degrading pathway. Bioresour Technol 2012; 124 : 83-9.

24. Hadibarata T, Tachibana S. Microbial degradation of $n$-eicosane by filamentous fungi. In: Interdisciplinary studies on environmental chemistry and environmental research in Asia. (Eds. Y. Obayashi, T. Isobe, A. Subramanian, S. Suzuki and S. Tanabe), Terrapub, Tokyo, 2009; 323-9.

25. Covino S, D’Annibale A, Stazi R, Cajthaml T, Čvančarová M, Stella T, Petruccioli M. Assessment of degradation potential of aliphatic hydrocarbons by autochthonous filamentous fungi from a historically polluted clay soil. Sci Total Environ 2015; 505: 545-54. 